\title{
Retinal vein obstruction and intraocular pressure: abnormal postural response independent of facility of outflow
}

\author{
BILLIE I. WILLIAMS AND W. S. PEART \\ From the Western Ophthalmic Hospital, London NW1, and the Medical Unit, St Mary's Hospital, \\ Praed Street, London W2
}

SUMMARY Eleven patients with a central retinal vein obstruction and 18 with a tributary vein obstruction were examined. The intraocular pressure of both eyes of each subject was measured while he was in the sitting position and again after he had been lying down for 15 minutes. Tonography was then carried out on both eyes. No correlation was found between the value of the coefficient of outflow and the magnitude of the rise in intraocular pressure occurring in any eye on the adoption of the supine position, and no correlation between the relative values of the coefficients of outflow in any pair of eyes and the occurrence of the obstruction in one eye rather than the other.

In a previous communication (Williams and Peart, 1978) we reported our finding that patients who have suffered a unilateral central or tributary retinal vein obstruction show a bilateral defect in the regulation of their intraocular pressure when they are subjected to a change in posture, namely, when they change from the sitting to the supine position. Thus in the subjects we examined the mean rise of pressure recorded in a group of normal eyes was $0.6 \pm 1.2 \mathrm{mmHg}$, while that recorded in patients with a central vein obstruction was $1.8 \pm 2.4 \mathrm{mmHg}$ in the eye with the lesion and $2 \cdot 6 \pm 2 \cdot 3 \mathrm{mmHg}$ in the contralateral eye and in patients with a tributary vein obstruction $3 \cdot 1 \pm 2.3 \mathrm{mmHg}$ in the eye with the lesion and $2 \cdot 1 \pm 2 \cdot 2 \mathrm{mmHg}$ in the contralateral eye.

These findings seemed to us to have 2 features of particular significance: (1) the abnormal response was present in both eyes; (2) it was similar to that shown by eyes with chronic simple glaucoma.

In our previous communication we referred to the studies of Inglima (1966), who performed a postural test on both eyes of patients with unilateral simple glaucoma and found an abnormal response in the glaucomatous eye only. His tonographic studies made on a series of normal and glaucomatous eyes showed a significant relationship between the facility of outflow and rise of intraocular pressure in response to change of posture. We also referred

Correspondence to Dr B. I. Williams, St Mary's Hospital, Praed Street, London W2 1NY. to the studies of Vannas and Tarkkanen (1960) and Bertelsen (1961), who performed tonography on both eyes of a number of patients with a unilateral central vein obstruction and found a somewhat superior facility of outflow in the obstructed eyes as compared with the contralateral.

With this work in mind we decided, as an initial investigation of the phenomenon we had found in our patients, to examine a further number of subjects with either a central or tributary vein obstruction in order to find out if they showed a correlation between (1) facility of outflow and magnitude of postural response and/or (2) facility of outflow and site of the obstruction, that is, in one eye as opposed to its fellow.

\section{Patients and methods}

We examined 2 groups of patients all of whom had received a preliminary clinical examination. They comprised (1) 11 cases of unilateral central vein obstruction; (2) 18 cases of tributary vein obstruction, 17 of which had a unilateral lesion and 1 a bilateral lesion.

The patients were selected irrespective of age, sex, the supposed aetiology of the obstruction, or the presence of systemic hypertension. The duration of the obstruction varied, and some were receiving coincident systemic therapy with drugs such as hypotensives, diuretics, etc. Two patients with central vein occlusions were receiving local treat- 
ment with pilocarpine drops; in one case to the eye with the obstruction in the other case to the contralateral eye.

The group of patients with central vein obstruction contained 7 males and 4 females. Their ages ranged from 59 to 74 years, mean 67.8 years. The group with tributary vein obstruction contained 14 males, one of whom had bilateral lesions, and 4 females. Their ages ranged from 41 to 79 years, mean 60.4 years.

\section{METHOD}

The patient was asked to sit quietly for 15 minutes near one end of an examination couch. Amethocaine $1 \%$ drops were then instilled into both conjunctival sacs, and the intraocular pressure was measured with the Alcon Applanation Pneumatonograph, the right eye being examined first. The first 2 tracings were disregarded (Langham, 1974) and a second pair of tracings made 5 minutes later. These were recorded. The patient was then asked to lie down for 10 minutes, when a second pair of tracings from the right and left eyes were recorded. (The value of the intraocular pressure was taken as the mean of the systolic and diastolic values on the tracing of the intraocular pulse.)

Tonography was then performed for 2 minutes on each eye and the coefficient of outflow derived in the usual way.

\section{Results}

From Table 1 it will be seen that our patients showed rises of intraocular pressure in response to change of posture, similar to those found in the first series of patients described in our previous paper. Thus in the case of patients with a central vein obstruction the obstructed eyes showed a mean rise of $3.8 \pm 2.0 \mathrm{mmHg}$ and the contralateral eye a mean rise of $3 \cdot 1 \pm 2 \cdot 2 \mathrm{mmHg}$, while in the case of unilateral tributary vein obstruction the obstructed eyes showed a mean rise of $5 \cdot 1 \pm 3 \cdot 3$

Table 1 Results of treatment

\begin{tabular}{lllll}
\hline & $\begin{array}{l}\text { Mean rise of } \\
\text { intraocular pressure } \\
\text { on lying }(\mathrm{mmHg})\end{array}$ & $\begin{array}{l}\text { Coefflcient of } \\
\text { outflow }\end{array}$ \\
\cline { 2 - 5 } & $\begin{array}{l}\text { Obstructed Fellow } \\
\text { eye }\end{array}$ & $\begin{array}{l}\text { Obstructed Fellow } \\
\text { eye }\end{array}$ & eye \\
\hline $\begin{array}{c}\text { Unilateral central } \\
\text { vein obstruction } \\
\text { (11 cases) }\end{array}$ & $3.8 \pm 2.0$ & $3 \cdot 1 \pm 2.0$ & $0.3 \pm 0.2$ & $0.2 \pm 0.1$ \\
$\begin{array}{c}\text { Unilateral tributary } \\
\text { vein obstruction } \\
\text { (17 cases) }\end{array}$ & $5.1 \pm 3.3$ & $3.8 \pm 2.6$ & $0.2 \pm 0.1$ & $0.2 \pm 0.1$ \\
\hline
\end{tabular}

$\mathrm{mmHg}$ and the contralateral eyes a mean rise of $3.8 \pm 2.6 \mathrm{mmHg}$. The patient with bilateral lesions showed a rise of $3.5 \mathrm{mmHg}$ in both eyes. As with those found in our first series of patients, these values are patently significant when compared with the mean value of $0.6 \pm 1.2 \mathrm{mmHg}$ which we found in normal eyes (Williams and Peart, 1978).

We analysed our results with respect to the following points: (1) the values found for the coefficients of outflow in both eyes of patients with a unilateral obstruction compared with the value $0.15 \mu \mathrm{l} / \mathrm{min} / \mathrm{mmHg}$ considered as the lower limit of normal; (2) the relative values for the coefficient of outflow in the obstructed and non-obstructed eye; (3) the relationship of outflow to the magnitude of rise in intraocular pressure associated with change in posture.

In order to find the value of the coefficient of outflow, the pressure of the eye was first recorded. The change in pressure occurring with a $10 \mathrm{~g}$ weight in place during the 2-minute tonography was then derived by drawing a straight line through the tonographic tracing and subtracting the pressure shown at the conclusion from the pressure at the beginning of the timed cycle. The simplified tables supplied for use with the Alcon tonometer were then used to find the coefficient of outflow by means of these two values. Our value for the normal is based on the results of studies with the Alcon tonometer (Langham, 1974). A group of normal eyes showed a mean value of $0 \cdot 28 \pm 0.01 \mu \mathrm{g} / \mathrm{min} /$ $\mathrm{mmHg}$, while a group of glaucomatous eyes showed a mean value of $0 \cdot 16 \pm 0.01 \mu \mathrm{l} / \mathrm{min} / \mathrm{mmHg}$.

\section{CENTRAL VEIN OBSTRUCTION}

We found that of the 11 cases 6 had coefficients of outflow in both eyes which were within the normal range, that is, greater than $0 \cdot 15$, and in most cases these indicated remarkably free drainage potential. Of the 5 remaining cases 3 showed frankly abnormal values in at least 1 eye. One patient had chronic open-angle glaucoma in his unobstructed eye, the second in her obstructed eye, and the third had no evidence of glaucoma but gave a history of a mother who died blind. A fourth patient, whose values were very near the lower limit of normal, had a pressure of $20 \mathrm{mmHg}$ in the obstructed eye (sitting position), a disc which showed early cupping, and a possible early field defect, but the fifth, whose obstructed eye had a low coefficient, had no evidence of glaucoma and no significant family history.

In 5 cases the facility of outflow was greater in the eye with the venous obstruction than in its colleague and in 5 cases the reverse was true. In one case (the first noted above) the values were equal and abnormal. Hence it appears that the 
magnitude of the rise of intraocular pressure associated with the change in posture is independent of the facility of outflow.

\section{TRIBUTARY VEIN OCCLUSION}

Of the 17 cases of unilateral branch vein obstruction 12 showed facilities of outflow within the normal range in both eyes, and again many of these indicated a remarkably free drainage potential. The remaining 5 all had 1 eye which had an abnormally low value. Of these, 2 had slightly raised pressures (measured in the sitting position), but no other signs of glaucoma-23 $\mathrm{mmHg}$ and $20 \mathrm{mmHg}$. There was no evidence of early glaucoma in any of the remaining 3 patients, but 1 gave a history of a father who had bilateral glaucoma.

In the case of the bilateral lesion both coefficients of outflow were well within the normal limits.

In 8 unilateral cases the facility of outflow was greater in the obstructed eye and in 8 cases the reverse was true. In the patient with bilateral lesions the outflow from one eye was considerably greater than the other $(0.48 \mathrm{c} / \mathrm{w} 0.24)$, yet the rise of pressure was equal in both eyes $(3.5 \mathrm{mmHg})$.

As in the case of patients with central vein lesions, it appears that the magnitude of the rise of intraocular pressure in response to change of posture is independent of the values of the coefficient of outflow.

\section{Conclusions}

Our results show that the abnormal postural pressure results we have found in our patients are independent of the outflow facility. They confirm the results found by Vannas and Tarkkanen (1960) and Bertelsen (1961) for central vein lesions. Patients with retinal vascular obstructive lesions show a postural response similar to that of patients with chronic simple glaucoma but differ from them in that their intraocular pressures are within the normal range when these are measured in the sitting position and may or may not rise into the pathological range when measured with the patient in the supine position. Clearly the stage of a sustained (and rising) intraocular pressure is associated with the presence of an impaired drainage system, but the postural pressure responses in our patients are not.

We gratefully acknowledge the support given by the Wolfson Foundation and the Joint Standing Research Committee, St Mary's Hospital, London W2.

\section{References}

Bertelsen, T. I. (1961). The relationship between thrombosis in the retinal veins and primary glaucoma. Acta Ophthalmologica, 39, 603-613.

Inglima, R. (1966). Effect of patient position on applanometer readings. Eye, Ear, Nose and Throat Monthly, 45, 64-69.

Langham, M. E. (1974). The applications of the Alcon Applanation Pneumatonograph to clinical ophthalmology. Surgical Products Division, Alcon Laboratories, Inc. P.O. Box 1959, Fort Worth, Texas 76101.

Vannas, S., and Tarkkanen, A. (1960). Retinal vein occlusion and glaucoma and its prognostic significance. British Journal of Ophthalmology, 44, 583-589.

Williams, I., and Peart, W. S. (1978). Effect of posture on the intraocular pressure of patients with retinal vein obstruction. British Journal of Ophthalmology, 62, 688-693. 